\title{
LA ALDEA FELIZ DE MAURICIO CRAVOTTO
}

Croquis para Villa Humboldt.

Fondo privado de la Fundación

Cravotto

\author{
Mary MÉndeZ \\ Profesora de Historia FARQ UdelaR-Montevideo \\ https://dx.doi.org/10.12795/astragalo.2016.i21.09
}

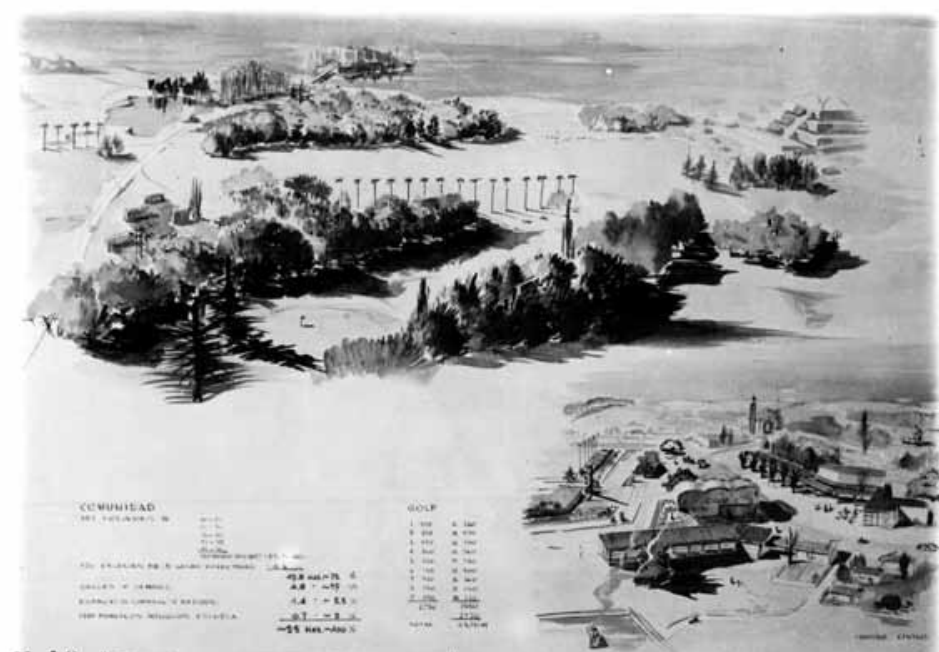

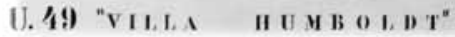

En la fotografía vemos los recaudos gráficos para una pequeña ciudad que pertenecen a la colección privada del arquitecto uruguayo Mauricio Cravotto ${ }^{1}$. Villa Humboldt, imaginada y nunca construida, debía estar localizada en el centro del Uruguay sobre el Río Negro y frente al lago artificial de la represa de Rincón del Bonete, en el sitio donde se genera la energía eléctrica que alimenta a todo al país. Las imágenes no contienen demasiados detalles del proyecto ni de su autor e incluso es probable que no se trate de un proyecto sino apenas de una sugestión urbanística. Posiblemente los dibujos hayan sido realizados para sugerir la atmósfera y el carácter buscados para la villa, de cara a su definición plástica, tema que fue planteado por Cravotto en 1949 como ejercicio del curso de Urbanismo que dirigía en la Facultad de Arquitectura.

La villa estaba integrada por viviendas, un centro cívico y comercial, áreas deportivas y edificios para el recreo. La pequeña comunidad se desarrollaría a partir del núcleo inicial, compuesto por unas 2000 personas, todos funcionarios del Geografeum, investigadores dedicados al estudio de la geografía, la zoología, la botánica, el paisaje y la ecología mundial, responsables también del archivo de documen- 
tación cartográfica y aereofotogramétrica. La institución, el núcleo de la aldea, seguía los pasos de Alexander von Humboldt, uno de los padres de la geografía moderna y estaba pensada para mantener encendida la antorcha de la Ilustración en suelo oriental.

Si nos detenemos por un instante en la fotografía, en el margen superior derecho vemos el Geografeum, el edificio en forma de pirámide escalonada que asoma junto al lago. Sigamos apenas el derrotero local de la singular forma, su aparición como museo acuático en el Plan Regulador para Punta del Este que Carlos Gómez Gavazzo realizó en 1935, unos meses después de terminar su estadía con Le Corbusier en París, para establecer así los explícitos vínculos con el Mundaneun. Es conocido el enfrentamiento entre Le Corbusier y el arquitecto checo Karel Teige, que tuvo entre sus temas el arcaísmo del museo para la Ciudad Mundial de 1929. Recordemos aquí que el zigurat fue rabiosamente defendido por el suizo como contrapunto simbólico para la mecánica ciudad moderna.

Siguiendo esa misma lógica, el Geografeum de Villa Humboldt expresa sus pretensiones simbólicas a través de la forma, mediante la evocación de una arquitectura que por arcaica ya se vuelve eterna, pero además refuerza esta pretensión a través del uso. El edificio cobija a un tipo de trabajadores y un tipo de conocimiento al que podríamos calificar como desinteresado e ideal. O mejor todavía, una sabiduría ajena a las formas de pensamiento operativo que gobiernan la producción moderna.

Villa Humboldt no es un conglomerado aislado, sino el corazón de todo un sistema urbano. Es la principal urbanización de una red de poblados dispersos por todo el territorio uruguayo que Mauricio Cravotto denominó Aldea Feliz. Mucho más que un proyecto, la Aldea Feliz fue una teoría general sobre las formas de los asentamientos humanos que llegó a articular todo el pensamiento de Cravotto y que le permitió unificar propuestas concretas, desde la escala edilicia a la territorial.

Para ello fue necesario recorrer un largo camino intelectual en el que el arquitecto comenzó pasando revista a los principios artísticos de Camilo Sitte, al pensamiento de Werner Hegemann y a las ideas comunitarias de la Ciudad Jardín de Ebenezer Howard. Recuperando la impronta de las ciudades medievales de Alemania e Italia intercambió datos y opiniones con una extensa red de intelectuales a lo largo y ancho del mundo.

Inicialmente la Aldea Feliz tuvo un marcado carácter romántico que puso en valor la naturaleza por encima de cualquier forma de vida metropolitana. Por eso las imágenes rurales y pintorescas, o la domesticidad de la vida comunitaria invocada en las aldeas medievales, fueron leídas en contraste con el rostro anónimo y la vida nerviosa de las grandes ciudades. De la misma manera, este renacer de comunidades y aldeas parecen ser la condición utópica y necesaria para el renacimiento paralelo de la arquitectura y en especial de los monumentos, representados por los edificios públicos.

Cravotto fue definiendo la idea de manera progresiva al comenzar la década del veinte, llegando a formalizarla completamente hacia 1955 y la explicó paralelamente en artículos, clases y conferencias. Los materiales que prueban el dilatado pensamiento se conservan en su archivo privado en carpetas y biblioratos. Uno de estos lleva por nombre Aldea Feliz y en sus folios incorporó edificios, premisas para los 
cursos de Urbanismo, artículos sobre vivienda y planes urbanos. En consecuencia, parece que todos los proyectos que Cravotto realizó deben entenderse como fragmentos de una utopía urbana en construcción.

El Palacio Municipal y el Plan Regulador para la ciudad de Montevideo fueron las dos propuestas que le permitieron iniciarla. La primera fue el anteproyecto que Cravotto presentó en el llamado a concurso de 1924. El Municipio iba a instalarse en el predio donde ya se había comenzado a construir el Palacio de Gobierno, sobre la Avenida 18 de Julio, entre las calles Ejido, Soriano y Santiago de Chile. Paralizado en 1910, los cimientos alcanzaban el medio metro por encima de la superficie y restringían la planta del nuevo edificio.
La fascinación finisecular que sobre Cravotto ejercían los ayuntamientos medievales se plasmó en el proyecto neogótico con el que obtuvo el premio más destacado. La planta se organizó en torno a dos claustros articulados por volúmenes que albergaban las salas principales. Los espacios abiertos contiguos otorgaban al conjunto la imagen de una pequeña ciudadela, como se revela claramente en el croquis. Una torre monumental se ubicaba sobre la avenida, jerarquizando el acceso principal al hall. El campanario, pues eso era en realidad la torre, debía otorgar belleza y paz al pueblo montevideano, dominando la plaza pública de modo similar a los de las ciudades belgas de Brujas y Malinas. Citando al austríaco Camilo Sitte, Cravotto destacaba el interés que generaban las visiones

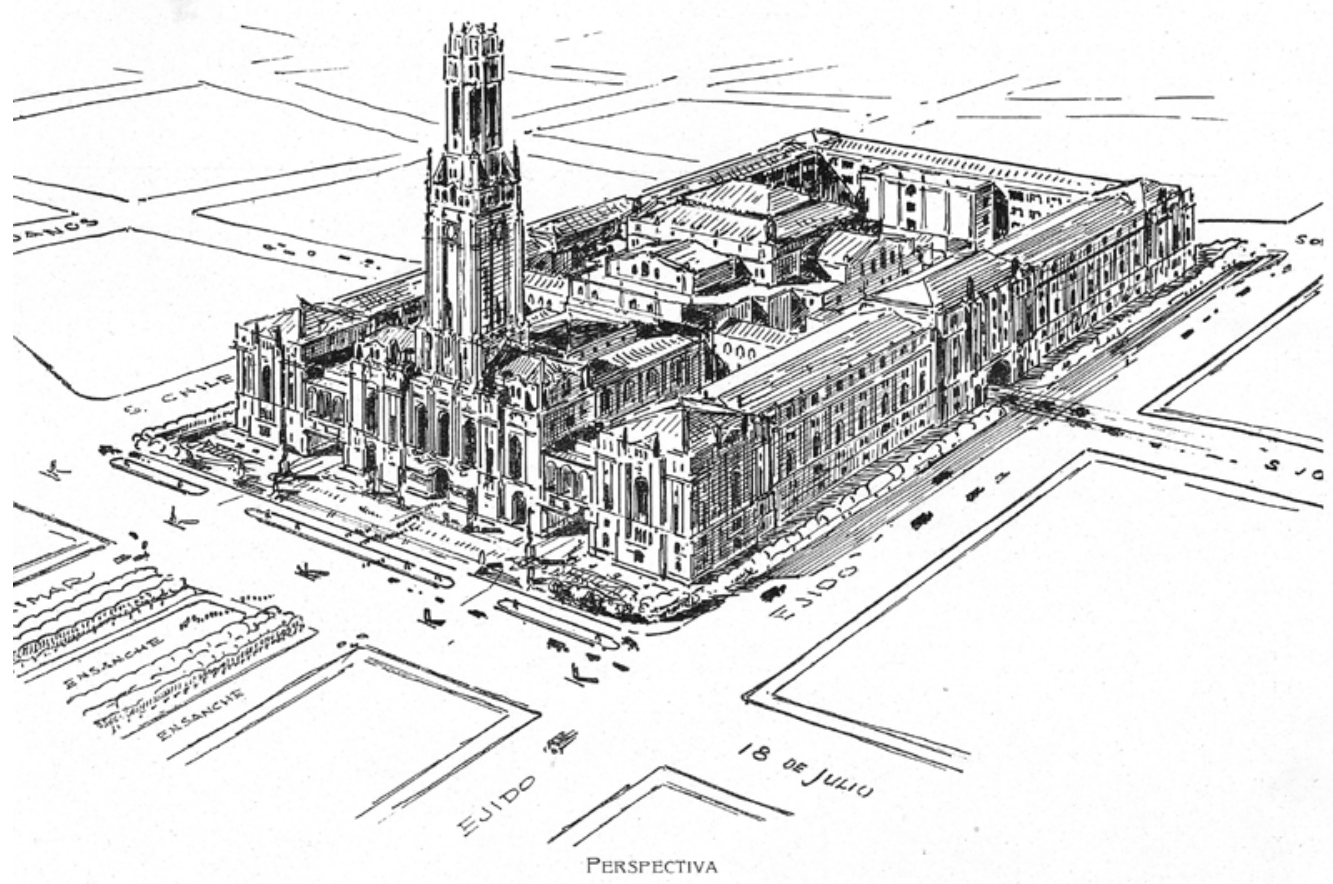

M. Cravotto, Palacio Municipal. Anteproyecto de 1924, Arquitectura (SAU), nº 78, (1924): 83. 
oblicuas del campanile, una vista que plasmó en varias perspectivas. En esta instancia el jurado declaró desierto el primer premio del concurso y Mauricio Cravotto obtuvo un segundo puesto, que no llegó a construirse. ${ }^{2}$

Entre julio de 1929 y diciembre de 1930 se realizó un nuevo concurso a dos vueltas en el cual Cravotto resultó finalmente ganador. $\mathrm{Ha}$ bían pasado cinco años y aunque los elementos estructuradores se mantuvieron, la evidente referencia estilística medieval del primer concurso se diluyó. El alto campanario persiste, pero bajo la forma de una torre escalonada, desplazada de la fachada principal hacia el centro del predio, mientras que la plaza frontal adquirió una relevancia mayor al elevarse varios escalones sobre la Avenida 18 de Julio y continuar francamente en el interior del edificio.

En paralelo Cravotto estaba definiendo junto a los arquitectos Octavio De los Campos, Milton Puente e Hipólito Tournier el Anteproyecto de Plan Regulador para la ciudad de Montevideo. La relación de la incipiente teoría con los postulados que revisaron la Ciudad Jardín de Howard en el período de entreguerras parece bastante explícita en este plan urbano. Allí se sostenía la alta densidad de población, la formación de conurbaciones, la limitación del número de los habitantes y la generación de otros centros separados del principal por un cinturón verde. La posición contraria de Cravotto a la proliferación de los suburbios jardín se advierte con claridad.

El Plan Regulador se basaba en la reubicación del centro de Montevideo hacia el norte, generando un Centro Cívico de Gobierno, punto de concentración que contrarrestara el desarrollo que se estaba operando hacia el Este de la ciudad y la limitación de la población hasta un máximo de 3 millones de habitantes. Proponía la multiplicación de espacios verdes en el interior de la ciudad y un nuevo sistema vial conformado por parkways que limitaban cada zona.

Hacia el norte, se limitaba la ciudad mediante una vía bordeada por árboles, donde se insertaban cincuenta rascacielos para habitación colectiva, con una capacidad total de 250000 habitantes. Se lograba de esta forma una alta densidad que definía al mismo tiempo el área urbanizada y la separaba nítidamente de la zona rural. El arco de torres debía absorber el crecimiento sin aumentar la mancha urbana y permitir el contacto de los ciudadanos con la naturaleza que comenzaba allí mismo, al pie de los edificios. Más allá, desarrolladas en un arco de círculo, se articulaba un conglomerado de aldeas: las ciudades jardín satélites. Las acciones propuestas debían lograr la felicidad social, no solo cuestión material, sino sobre todo espiritual. ${ }^{3}$

Mauricio Cravotto avanzó en la definición de la teoría con el proyecto para el Parkway Atlántico que debía unir Montevideo con Piriápolis, una propuesta elaborada entre 1932 y 1936. Los dos principios claves de la región de Nueva York se aplicaron aquí: el de la unidad vecinal y el de carretera arbolada en la versión reformulada por Barry Parker. ${ }^{4}$ El parkway fue traducido como una avenida con 700 árboles por hectárea. Era una vía que unía aldeas -algunas eran los balnearios existentes en $\mathrm{Ca}$ nelones- enlazando la ciudad con el campo y permitiendo establecer relaciones productivas entre ambos. En este caso Cravotto retomó los argumentos centrales de Howard, no solamente en lo relativo a la articulación física sino a algo mucho más importante para el modelo, el modo colectivo de propiedad de la tierra. 
El Park-way Atlántico fue concebido como un parque lineal extenso de propiedad estatal: cientos de hectáreas de bosque libres de la especulación del suelo. En ese bosque público se insertarían núcleos habitados, aldeas de hasta 5000 habitantes. El plan evitaba las construcciones enfrentadas a la avenida, que se colocaban en cambio sobre caminos vecinales que la cruzaban perpendicularmente. La avenida era una senda de velocidad controlada de 100 kilómetros de extensión que atravesaría diversos paisajes. Árboles, flores y cultivos debían intercalarse con las aldeas y otros poblados más pequeños de hasta 800 habitantes. Esos pueblos menores albergarían artesanos y agricultores y en ellos se instalarían paradores y hoteles para los viajeros. Sobre la avenida se ubicarían también las colonias de vacaciones de los distintos gremios de trabajadores.

Las ideas que iban conformando la teoría de la Aldea Feliz fueron la base sobre la que se estableció el curso de Urbanismo que dictaban Cravotto y Juan Antonio Scasso en la Facultad de Arquitectura. Todos los anteproyectos que propusieron fueron montados sobre esta teoría de modo que desde la década del 30 los estudiantes trabajaban en partes o sectores de un plan general. Cravotto fue avanzando desde la enseñanza en los conceptos teóricos, en la configuración de los principales componentes, en la aplicación de referentes en ocasiones bastante explícitos y en las imágenes asociables que suponía más pertinentes.
El anteproyecto de Plan para la ciudad de Rocha, la Ciudad Industrial de Rincón del Bonete o el Pueblo del Mármol propuestos en 1935 fueron ejemplos contundentes de base industrial, que incorporaban vías de tránsito arboladas, evitaban la rigidez del damero y destinaban gran parte del suelo a espacios verdes en las proximidades de la zona de viviendas. ${ }^{5}$ El Plan para el Cerro exploraba la capacidad evocativa de los pueblos mediterráneos incorporando imágenes pintorescas para los caseríos y aprovechando las diferencias de niveles que caracterizan el sitio. Las visuales interrumpidas, las calles ondulantes, la relación próxima entre los edificios, el borde cerrado de las plazas con centros vacíos eran tópicos que se alineaban indudablemente con la tradición del Arte Urbano difundido por Sitte.

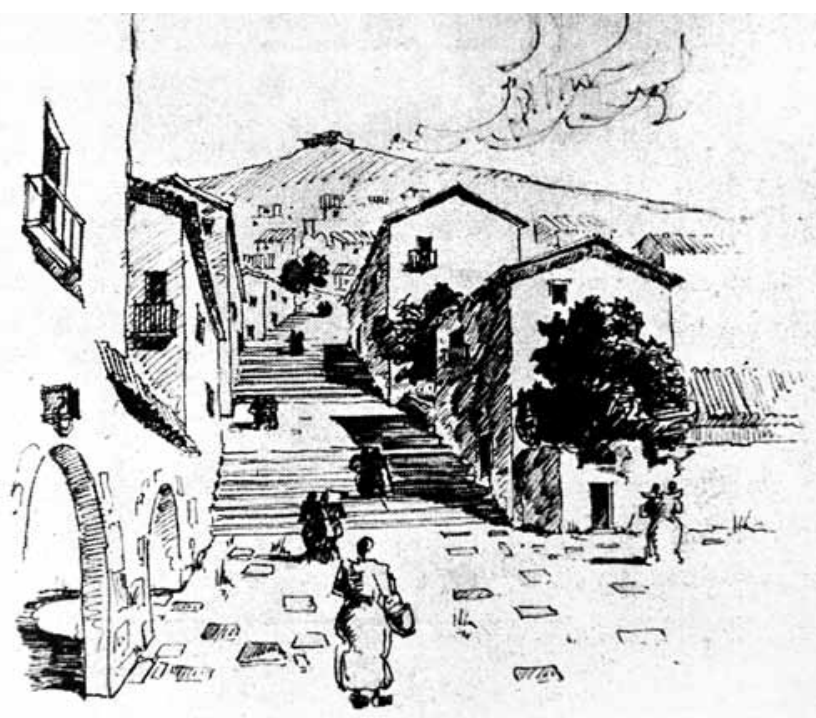

El Cerro. Curso de Urbanismo, Revista Arquitetura e Urbanismo (Rio de Janeiro, marzo-Abril 1938) 
En 1941, el concurso para el Plan de Mendoza, en Argentina, representó otra ocasión para poner en práctica buena parte de la teoría. ${ }^{6}$ Obtenido el primer premio, Cravotto y Scasso, junto con los argentinos Fermín Bereterbide y Alberto Belgrano Blanco definieron tres etapas consecutivas siguiendo la operativa que solía usarse en el Instituto de Urbanismo, que entonces era dirigido por Cravotto. ${ }^{7} \mathrm{El}$ Pre-plan estaba basado en los datos primarios obtenidos y pretendía definir un plan de acciones inmediatas para evitar que se agravaran los problemas de la ciudad. Estaba regido por una serie de conceptos claves aunque bastante abstractos como la idea de justicia, entendida como una concertación urbana que debía permitir a cada uno de los habitantes la posibilidad de comprender, sentir, hacer y dejar hacer la obra armónica y participar de la felicidad colectiva. ${ }^{8}$
Siguiendo las lógicas de la Aldea Feliz, el Plan presentaba como prerrogativa fundamental la transformación de tierras privadas en públicas para poder operar libremente de acuerdo a las conveniencias generales, eliminando los intereses de los privados que siempre obstaculizan el bien común. Liberando la propiedad de la tierra se proponía mejorar el uso del suelo y del subsuelo, aprovechando la zona de serranías para habitación, cultivo y forestación.

Los arquitectos buscaban dotar a Mendoza de ciertos elementos con carácter urbano para convertirla en una ciudad sin perder la benéfica impronta de conglomerado aldeano que debía no sólo mantenerse sino potenciarse. De acuerdo con esto, no se pretendía aumentar la densidad ni el tamaño del núcleo sino solucionar problemas viales y funcionales, al tiempo que definir una ciudad con alma con una armo-

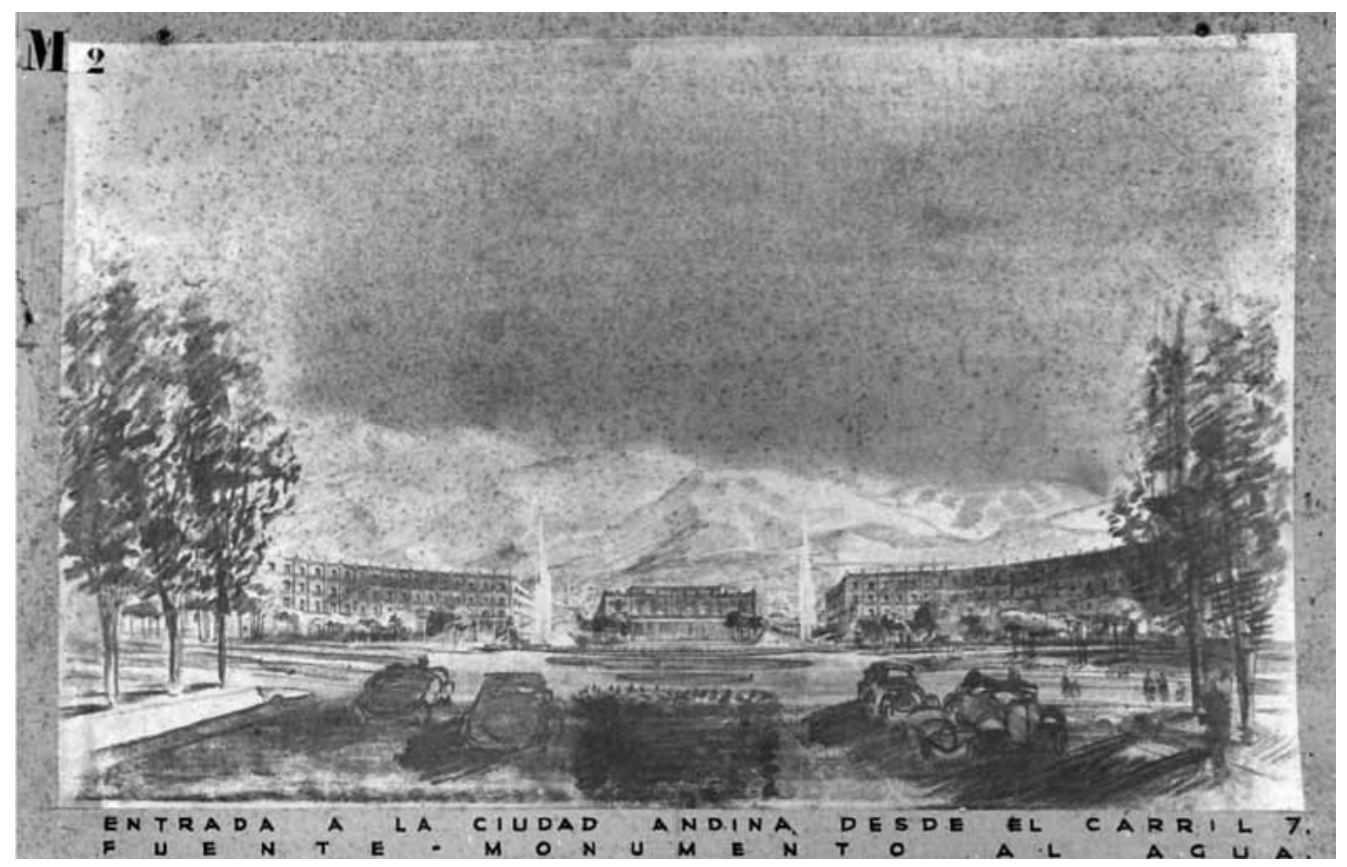

Plan Regulador de Mendoza. Fondo privado de la Fundación Cravotto. 
nía interior perfecta. Señalaban que para esto no se precisaba un gran tamaño sino fuerza de procreación y poder armónico de expansión para producir núcleos satélites capaces de albergar otros habitantes evitando el crecimiento suburbano. El Plan Regulador de Mendoza significó una puesta a punto de la teoría de la Aldea y una aplicación a un caso real. Fue sancionado en diciembre de 1942 y su gestión se aprobó inmediatamente. Sin embargo el derrocamiento del gobierno conservador por parte del movimiento militar que tuvo lugar en 1943 frustró la iniciativa.

En 1955 Cravotto explicó de manera acabada su teoría en el artículo La Aldea Feliz, una teoría para distribuir armónicamente la población en crecimiento del Uruguay, publicado en el Diario Acción. Consistía en una red compuesta por diez aldeas y otras diez comunidades mayores que colonizarían el territorio uruguayo, conectadas por avenidas rodeadas de parques. ${ }^{9}$ Así se llegaría a poblar las zonas centrales con unos 700000 habitantes con un temperamento aldeano, explícitamente contrario a los indolentes urbanitas que vivían en las grandes ciudades. Las aldeas eran económicamente estables y se diferenciaban según el tipo de producción de base artesanal o industrial. Proponía forestar la red vial con lo que se alcanzaría unos 2000 $\mathrm{km} 2$ arbolados, mejorar las vías férreas y liberar la tenencia de la tierra en las rutas y zonas de asentamiento de los pueblos, principalmente las áreas destinadas a las viviendas y promover también el desarrollo de la ecología a través del Geografeum.

En el artículo Cravotto cita como referentes algunos ejemplos relevantes comenzando por la acción de la Tennessee Valley Authority, la agencia creada en 1933 por Roosevelt para generar energía eléctrica en una amplia región de los Estados Unidos en los tiempos del New Deal. Recordemos aquí que su Villa Humboldt, la urbanización principal de La Aldea Feliz, se ubicaba en el mismo sitio de la represa hidroeléctrica del Rincón del Bonete.

La armonía entre industria y cultura, es decir, el rostro humano de la fábrica, es ejemplificada a través de la acción de Adriano Olivetti en Ivrea, ciudad visitada y reseñada con atención por Cravotto en 1953. Continúa con la acción de Richard Neutra en las comunidades modernas de California, Puerto Rico y Guam, la organización cooperativa de Suecia, la urbanización regional industrial del valle del Ruhr y los planes ingleses de posguerra, todos ellos indicados como experiencias asociables a la Aldea Feliz. El texto del planificador inglés Thomas Sharp, The Anatomy of the Village, que había sido publicado en inglés en 1946, es traducido por Cravotto como Anatomía de la Aldea, indicando que contiene notable información sobre los distintos ejemplos.

El artículo apareció el día 24 de agosto y ocupó una página completa del diario Acción. El medio de prensa pertenecía el Partido Colorado y había sido creado por Luis Batlle Berres, quien en 1955 gobernaba el país como presidente del Consejo Nacional de Gobierno. Resulta significativo señalar el interés político que en ese momento revestía la teoría de la Aldea Feliz, justo cuando Uruguay comenzaba a transitar tiempos de angustia económica y dramáticos problemas financieros. La editorial agregó al artículo de Cravotto una breve nota titulada 1825-Agosto-1955, en alusión a la fecha, víspera de los 130 años de la Declaratoria de la Independencia. Allí se exhortaba a recordar las 
obligaciones republicanas de los uruguayos, a emular el legado de los mayores que con sacrificio y trabajo habían hecho prosperar al país concluyendo con un esperanzado llamado del gobierno para que cada ciudadano sepa cumplir con su deber.

\section{NOTAS}

1 Cravotto nació en Montevideo en 1893 y murió en la misma ciudad en 1962. Estudió arquitectura entre 1912 y 1917 , ganó el Gran Premio de la Facultad de Arquitectura en 1918 y en usufructo de la beca obtenida realizó hasta 1921 un viaje de estudios por la costa pacífica de América del Sur, Estados Unidos y Europa. En París ingresó en el taller libre del urbanista León Jaussely. A su regreso comenzó su carrera docente en los cursos de Composición Decorativa y Proyecto de Arquitectura. Enseñó urbanismo con Juan Antonio Scasso desde 1923. La bibliografía del curso incluía los textos de Ebenezer Howard, Raymond Unwin, León Jaussely, Tony Garnier, Lewis Mumford y George Simmel. Por lo tanto la vertiente teórica más importante se apoyaba en la Ciudad Jardin en todas sus variantes incluidas la francesa y la norteamericana. Promotor de la inserción de los estudios urbanos en la carrera, creó el Instituto de Urbanismo en 1936, que dirigió hasta su renuncia en marzo de 1953. Dentro de su actividad profesional destacan el Rowing Club de Montevideo obtenido por concurso en 1923, el Palacio Municipal construido entre 1936 y 1962, el Hotel Rambla de 1931 y su casa propia de 1933.

2 Mauricio Cravotto, Concurso del Palacio Municipal, Arquitectura (SAU), $\mathrm{n}^{\circ} 78,(1924): 83$.
3 Mauricio Cravotto y otros, Anteproyecto de Plan Regulador de Montevideo, Arquitectura (SAU), nº160 (1931)

4 La incorporación de otros principios de planificación de origen norteamericano probablemente se debía a la lectura de los textos de Lewis Mumford, de los que Cravotto era asiduo lector.

5 Instituto de Urbanismo da Facultade de Arquitetura de Montevideo, Arquitetura e Urbanismo, n ${ }^{\circ} 225$ (Setiembre-Octubre de 1937).

6 El caso está ampliamente reseñado en Méndez, Mary. Mendoza, la argentina Aldea Feliz de Mauricio Cravotto. Revista Vitruvia ${ }^{\circ} 1$, Montevideo: oct. 2014. Revista del Instituto de Historia de la Arquitectura. Farq. UdelaR.

7 Mauricio Cravotto, Plan regulador de la ciudad de Mendoza, República Argentina, por los arquitectos F.H. Bereterbide, A.B. Blanco, M. Cravotto y J.A. Scasso, 8 (Montevideo.: Instituto de Urbanismo, Facultad de Arquitectura, 1942-1943).

8 Mauricio Cravotto, Posiciones y conceptos, Plan regulador de la ciudad de Mendoza.

9 Mauricio Cravotto. La Aldea Feliz, una teoría para distribuir armónicamente la población en crecimiento del Uruguay, Diario Acción, 2417 (Montevideo: agosto 24). 